\title{
Identification of volatile compounds from polyolefin used for food packaging
}

\author{
Q. Z. Su, P. Vera, E. Canellas, C. Nerín \\ I3A, University of Zaragoza, Campus Rio Ebro, María de Luna 3, 50018 Zaragoza \\ Tel. +34-652666612, email: sukissqz@gmail.com
}

\begin{abstract}
Identification of volatile compounds from different virgin polyolefin FCMs was carried out by GC-MS with both HS-SPME and ultrasonic extraction (UE), with the aim to obtein the most amount of volatile compounds from polyolefin. Seventy compounds were identified with $90 \%$ reliability by GC-MS with NIST 14 library, most of them are NIAS.
\end{abstract}

\section{Introduction}

Polyolefin is widely used as film, tray and container etc. for food contact. Nowadays, growing concern has risen owing to the potential migration of non-intentionally added substances (NIAS) from these materials. It is quite a tedious and difficult work, however, hence different complementary techniques are necessary to cover as wider as possible range of potential migrants. Atmospheric Pressure Gas Chromatography Coupled to a Quadrupole Hyphenated to a Time of Flight (APGC-QTOF) is an emerging technique, which is of great help to elucidate volatile unknown compounds because of having the ability to keep both molecular and fragment ions of volatile compounds with high resolution mass. Using gas chromatography mass spectrometry (GC-MS) with commercially available library e.g. NIST can identify most of the volatile compounds with acceptable reliability, which in return can greatly reduce the number of peaks needed to be identified by APGC-QTOF using the same gas chromatography condition. The objective of this study is to identify as more as possible compounds employing GC-MS with NIST 14 library, with the aim to reduce qualification work when using APGC-QFOT.

\section{Method and materials}

5 polypropylenes, 3 polyethylenes, and 1 polystyrene samples were cut into small pieces seperately. For HS-SPME, $1.00 \mathrm{~g}$ of sample was directly extracted with a gray fiber $(50 / 30 \mu \mathrm{m}$ $\mathrm{DVB} / \mathrm{CAR} / \mathrm{PDMS})$. Extraction temperature and time were $80^{\circ} \mathrm{C}$ and 15 minutes, respectively.
For ultrasonic extraction, $1.00 \mathrm{~g}$ of sample was put into a vial, and then $5 \mathrm{~mL}$ of dichloromethane was added to perform extraction in an ultrasonic machine for $1 \mathrm{~h}$. The extraction was applied two times, each of which used new dichloromethane to extract as more compounds as possible. After extraction, sample concentrator was used to concentrate the extract until ca. $2 \mathrm{~mL}$. Finally, the concentrate extract was injected in GC-MS. The condition of GC-MS analysis is as followed: HP5MS (30 $\mathrm{m} \times 0.25 \mathrm{~mm}$ diameter $\times 0.25 \mu \mathrm{m}$ internal thickness) column, temperature program: $50{ }^{\circ} \mathrm{C}(5$ $\mathrm{min}) / / 10^{\circ} \mathrm{C} / \mathrm{min} / / 300{ }^{\circ} \mathrm{C}(2 \mathrm{~min})$, inject volume 1 $\mu \mathrm{L}$ with splitless mode, helium flow $1.0 \mathrm{~mL}$, solvent delay $5 \mathrm{~min}$, and scan mode from 40-650 amu.

\section{Results}

From the polyolefin studied, 17 compounds were identified by GC-MS with NIST 14 library with at least $90 \%$ match, most of which are NIAS (table 1). As we can see, compared to PP and PS, only very few compounds have been detected in PE. Furthermore, ultrasonic extraction resulted in much more compounds than HS-SPME

\section{Conclusion}

GC-MS with NIST 14 library has been employed to identify volatile compounds from 3 kinds of polyolefin in an attempt to reduce qualification work when applying APGC-QTOF to identify NIAS. Finally, 17 volatile compounds have been identified with at least $90 \%$ match, most of which are NIAS. However, at the next stage, using standards to confirm the identification as well as employing APGC-QTOF to identify the rest of peaks are necessary.

\section{REFERENCIAS}

[1]. CANELlAS, E., VERA, P., DOMEÑO, C., ALFARO, P. et NERÍN, C. Atmospheric pressure gas chromatography coupled to quadrupole-time of flight mass spectrometry as a powerful tool for identification of non intentionally added substances in acrylic adhesives used in food packaging materials. Journal of 
Chromatography A. 2012, 1235, 141-148. DOI 10.1016/j.chroma.2012.02.039.

[2]. CHERTA, L., PORTOLÉS, T., PITARCH, E., BELTRAN, J., LÓPEZ, F. J., CALATAYUD, C., COMPANY, B. HERNÁNDEZ, F. Analytical strategy based on the combination of gas chromatography coupled to time-of-flight and hybrid quadrupole time-offlight mass analyzers for non-target analysis in food packaging. Food Chemistry. 2015, 188, 301-308. DOI 10.1016/j.foodchem.2015.04.141.

[3]. WU, C. P., QIAN, K. N., WALTERS, C. C. MENNITO, A. Application of atmospheric pressure ionization techniques and tandem mass spectrometry for the characterization of petroleum components. International Journal of Mass Spectrometry. 2015,377, 728-735. DOI 10.1016/j.ijms.2014.08.019.

[4]. PANSERI, S., CHIESA, L. M., ZECCONI, A., SONCINI, G., DE NONI, I. Determination of Volatile Organic Compounds (VOCs) from wrapping films and wrapped PDO Italian cheeses by using HS-SPME and GC/MS. Molecules. 2014, 19, 8707-8724. DOI 10.3390/molecules19078707.

Table 1. Identified compounds by GC-MS with at least $90 \%$ match

\begin{tabular}{|c|c|c|c|c|}
\hline Materials & $\begin{array}{l}\text { Extraction } \\
\text { method }\end{array}$ & Name of compounds & $\begin{array}{l}\text { Match } \\
(\%)\end{array}$ & Possible origin \\
\hline \multirow[t]{6}{*}{ PP } & UE & 2,4-Di-tert-butylphenol & 96 & NIAS \\
\hline & & $\begin{array}{c}\text { Benzenepropanoic acid, 3,5-bis(1,1-dimethylethyl)-4- } \\
\text { hydroxy-, methyl ester }\end{array}$ & 95 & NIAS \\
\hline & & $\begin{array}{l}\text { Hexadecanoic acid, 2-hydroxy-1-(hydroxymethyl)ethyl } \\
\text { ester }\end{array}$ & 95 & unknow \\
\hline & & Dodecanoic acid, 1-(hydroxymethyl)-1,2-ethanediyl ester & 96 & unknow \\
\hline & HS-SPME & .alpha.-Pinene & 94 & $\begin{array}{l}\text { constinuent of } \\
\text { essential oil }\end{array}$ \\
\hline & & $\begin{array}{l}\text { (1S,4aS,4bS,7S,8aS,10aS)-7-Isopropyl-1,4a- } \\
\text { dimethyltetradecahydrophenanthrene }\end{array}$ & 94 & unknow \\
\hline \multirow[t]{3}{*}{$\mathrm{PE}$} & UE & $\begin{array}{l}\text { (1S,4aS,4bS,7S,8aS,10aS)-7-Isopropyl-1,4a- } \\
\text { dimethyltetradecahydrophenanthrene }\end{array}$ & 97 & unknow \\
\hline & & 7,9-Di-tert-butyl-1-oxaspiro(4,5)deca-6,9-diene-2,8-dione & 99 & NIAS \\
\hline & HS-SPME & n-Nonylcyclohexane & 91 & unknow \\
\hline \multirow[t]{8}{*}{ PS } & UE & 2,4-Di-tert-butylphenol & 97 & NIAS \\
\hline & & 3,5-di-tert-Butyl-4-hydroxybenzaldehyde & 91 & NIAS \\
\hline & & 2,6-Diisopropylnaphthalene & 96 & unknow \\
\hline & & 7,9-Di-tert-butyl-1-oxaspiro(4,5)deca-6,9-diene-2,8-dione & 99 & NIAS \\
\hline & & $\begin{array}{l}\text { Benzenepropanoic acid, 3,5-bis(1,1-dimethylethyl)-4- } \\
\text { hydroxy-, methyl ester }\end{array}$ & 94 & NIAS \\
\hline & HS-SPME & Butylated Hydroxytoluene & 97 & antioxidant \\
\hline & & Phenol, 2,6-bis(1,1-dimethylethyl)-4-ethyl- & 91 & NIAS \\
\hline & $\begin{array}{l}\text { UE and HS- } \\
\text { SPME }\end{array}$ & Benzene, 1,1'-(1,3-propanediyl)bis- & 94 & NIAS \\
\hline
\end{tabular}

